\title{
Estrogen Exposure, Obesity and Thyroid Disease in Women with Severe Pulmonary Hypertension
}

\author{
Lori Sweeney ${ }^{1}$ and Norbert F. Voelkel ${ }^{2}$ \\ ${ }^{1}$ Endocrinology and Metabolism Divison and ${ }^{2}$ Pulmonary and Critical Care Medicine Division, \\ Department of Internal Medicine, Virginia Commonwealth University, Richmond, VA, USA
}

\begin{abstract}
Severe pulmonary hypertension is a lethal group of disorders which preferentially afflicts women. It appears that in recent years the patient profile has shifted towards older, obese, and postmenopausal women, suggesting that endocrine factors may be important. Several studies have revealed an increased prevalence of thyroid disease in these patients, but no studies have evaluated for a coexistence of endocrine factors. In particular, no studies have attempted to evaluate for concurrent thyroid disease, obesity and long-term estrogen exposure in patients.

88 patients attending the Pulmonary Hypertension Association 8th International meeting completed a questionnaire and were interviewed. Information was collected regarding reproductive history, height, weight, and previous diagnosis of thyroid disease.

$46 \%$ met criteria for obesity. $41 \%$ reported a diagnosis of thyroid disease. $81 \%$ of women reported prior use of hormone therapy. $70 \%$ reported greater than 10 years of exogenous hormone use. $74 \%$ of $\mathrm{fe}-$ male patients reported two or more of potentially disease modifying endocrine factors (obesity, thyroid disease or estrogen therapy).

The coexistent high prevalence in our cohort of exogenous estrogen exposure, thyroid disease and obesity suggests that an interaction of multiple endocrine factors might contribute to the pathogenesis of pulmonary hypertension and may represent epigenetic modifiers in genetically-susceptible individuals.
\end{abstract}

Key words: Severe pulmonary hypertension, Estrogen, Menopause, Thyroid Disease, Autoimmunity, Obesity

\section{INTRODUCTION}

Severe pulmonary arterial hypertension continues to be categorized as idiopathic pulmonary arterial hypertension (IPAH) or secondary pulmonary hypertension associated with various disease states (APAH). The WHO pulmonary hypertension classification system includes categories of pulmonary arterial hypertension (PAH), pulmonary hypertension attributable to chronic left heart, lung or thromboembolic disease and "miscellaneous" forms [1]. Whereas thirty years ago idiopathic or then called "primary" pulmonary hypertension was recognized as a disease of young women [2] and the NIH-sponsored pulmonary hypertension registry reported a female to male ratio of $1.7: 1$ [3], it appears that in recent years the patient profile has changed. The average patient diagnosed with IPAH is now older and frequently, a postmenopausal woman. The overall number of female patients also appears to have increased or is potentially overrepresented in clinical trials [4]. Data from the 2007 REVEAL registry report that $78 \%$ of 1226 patients with PAH were women with a median age of 53 years [5] and a large referral center reported on 657 patients with PAH, of which $77 \%$ were women and the mean age was 54 years [6]. In 2006, Taraseviciute published a retrospective medical record analysis of 1367 patients with severe $\mathrm{PAH}$ which revealed that 541 of these patients were postmenopausal women and that 217 of the women had a BMI $>30 \mathrm{~kg} / \mathrm{m}^{2}$ [7]. The discovery of the familial IPAH gene, BMPRII [8] and of the association of ALK-1 gene mutations in patients with hereditary hemorrhagic telangiectasia $(\mathrm{HHT})$ and $\mathrm{PAH}$ [9] provide the solid foundation for the concept of a genetic PAH predisposition. It has, however, been recognized that only about $50 \%$ of patients with germline BMPRII mutation develop severe PAH [10] and that the incidence of PAH in groups of patients with acknowledged risk factors, such as HIV infection or anorexigen drug intake, is low [11-12]. Remarkably, even in patients with significant intra-cardiac shunt, the fraction of patients who develop PAH is small. This raises the question whether there are additional previously unrecognized factors which, in concert with known trigger factors, can modify the risk of PAH development.

The shift in the patient profile towards older, obese, and postmenopausal women led us to postulate that there may be two previously unrecognized endocrine factors, which, when added to the genetic PAH susceptibility, may not only increase the risk of PAH development but also may be pathobiologically important. These factors include obesity, now recognized as a state of systemic inflammation [13] and exposure to potentially angiogenic estrogens in the form of hormone therapy for contraception or management of menopause. The concept of endocrine modulators in $\mathrm{PAH}$ is not entirely new. For example, several studies have reported an increased prevalence of autoimmune thyroid disease in PAH patients as compared to population based studies [14]. As autoimmunity, inflammation and angiogenesis [15-16] may each contribute to the patho- 
genesis of severe $\mathrm{PAH}$, we developed a questionnaire and conducted an interview in order to obtain information regarding these putative endocrine risk factors in patient volunteers assembled at the 2008 biannual meeting of the Pulmonary Hypertension Association. In particular, information regarding reproductive history, thyroid disease, height and weight was obtained. In the design of the questionnaire we were guided by epidemiological studies in hormone responsive cancers conceived to shed light on possible associations between reproductive history and cancer development [17]. Here we present data which suggest that obesity, hormone therapy and thyroid disease are frequent findings in this group of patients with severe PAH.

\section{Methods}

\section{Study Population}

Patients attending the Pulmonary Hypertension Association $8^{\text {th }}$ International Pulmonary Hypertension Conference and Scientific Sessions (Houston, TX) were recruited for enrollment in the study. This conference is a forum for interactions between $\mathrm{PH}$ patients, motivated to learn about their disease, and $\mathrm{PH}$ clinicians and researchers. In recent years the conference has provided a "research room" for the purposes of recruitment of $\mathrm{PH}$ patients and to facilitate the collection of blood and clinical samples. Patients were considered eligible for our study if they reported a diagnosis of pulmonary hypertension, were currently receiving medical treatment for $\mathrm{PAH}$ and were able to give informed consent. IRB approval was obtained prior to the initiation of this study.

\section{Medical History}

Questions regarding the medical history included: current age, height, weight, age at diagnosis of $\mathrm{PH}$, and current medications (in particular the use of prostacyclin or prostacyclin analogues). Patients were also asked about the "likely cause" of their pulmonary hypertension as it had been explained to them by their physician. Patients were also asked whether they had known family members with $\mathrm{PH}$ and to report the gender of these pulmonary hypertension patient relatives.

\section{BASELINe Survey}

Informed consent was obtained from each participant before study enrollment. A self-administered questionnaire which included the pertinent history regarding diagnosis and treatment of $\mathrm{PH}$, current medications, family history of $\mathrm{PH}$, reproductive history and history of thyroid disease was distributed to all consented patients. Completed questionnaires were collected within 2 subsequent days from 89 patients.

\section{PATIENT INTERVIEW}

A standardized interview was conducted by a board-certified endocrinologist for the purpose of allowing the patients to ask questions and for further explanation of their written responses. All interviews were conducted by L.B.S.; and the average length of the interview was 10 minutes.

\section{Reproductive Factors and Hormone Use}

Questions regarding reproductive factors included age at menarche, menstruation status, regularity of menstruation, length of menstruation, history of hysterectomy/oopherectomy, history of infertility (inability to become pregnant despite attempts greater than 1 year), history of polycystic ovarian syndrome (PCOS), history of pregnancy and live birth, history and length of breastfeeding, type of menopause (natural or induced) and history of exogenous estrogen exposure (female hormone treatment and ingestion of phyto-estrogens). Information collected on hormone treatment included current or past use of contraceptive agents (oral, transdermal, injection, and IUD) and agents initiated for menopause symptoms (oral preparation, transdermal preparation, vaginal estrogen cream). No questions were asked regarding dose or composition (estrogen/progestin) of hormone therapy given the anticipated difficulty in patient recall for these details [18]. Patients were instructed, however, to estimate the total duration of therapy for each agent. Patients were also asked about their personal history of hormone responsive cancers (breast or ovarian cancer) and history of anti-estrogen therapy.

\section{LiFELONG ESTROGEN EXPOSURE}

There is growing evidence to support the role of endogenous estrogens in the development of certain hormone responsive cancers [19]. Greater lifelong exposure to ovarian estrogen as occurs with early menarche, null parity and late menopause is associated with increased risk for the development of breast, endometrial and ovarian cancer in premenopausal women [20]. In postmenopausal women higher circulating estrogen levels are observed in obesity and these factors may act synergistically to confer increased risk in the development of hormone responsive cancer [21]. Although the risk of breast cancer associated with exogenous estrogen is somewhat controversial, current evidence suggests that prolonged estrogen therapy increases the risk of breast cancer, especially among younger women (age $<25$ years) [22].

There has been recent interest in the relationship between hormone responsive cancer and soy-derived isoflavone ingestion. Soyfoods (isoflavones) have estrogen-like properties under certain conditions and may stimulate the growth of estrogen sensitive breast tumors [23]. Many women incorporate soyfoods into their diets to attenuate vasomotor symptoms of menopause [24].

In an effort to quantify cumulative lifelong endogenous and exogenous estrogen exposure, we evaluated subjects according to several major epidemiologic risk factors which have been previously identified in studies of hormone responsive cancers. These include obesity, parity, total years of menstruation, use exogenous female hormones, history of ovarian or breast cancer, and ingestion of soy isoflavones. Based on 
Table 1.

\section{Estrogen Exposure Factor}

Points

BMI

$$
\begin{aligned}
& >25 \mathrm{~kg} / \mathrm{m} 2 \\
& >30 \mathrm{~kg} / \mathrm{m} 2
\end{aligned}
$$

$+1$

$+2$

Nulliparous

Menstruation

$>30$ yrs

$>35$ yrs

$+1$

$+2$

Exogenous hormones

$\begin{array}{ll}>10 \text { yrs } & +1 \\ >15 \text { yrs } & +2 \\ >20 \text { yrs } & +3\end{array}$

History of breast cancer

$+1$

History of ovarian cancer

$+1$

History of breastfeeding

$>24$ months

$-1$

Isoflavone ingestion

$>5$ serving per week

$+1$

these factors we generated an arbitrary scoring system to characterize the extent and contribution of each element to the overall long-term estrogen exposure. Table 1 shows the elements of this scoring system. The total number of possible points for each subject was 12 .

\section{THyroid DisEASE}

Participant PH patients were asked whether they had ever been diagnosed with thyroid disease and whether they had ever been on thyroid replacement therapy. During the patient interview, the interviewer asked further questions to clarify the type of thyroid disease (hypothyroidism, hyperthyroidism, thyroid cancer) reported by participants and to clarify whether the disorder required medical therapy (drug therapy, surgery or radioactive iodine). The form of thyroid disease and the treatment, if any, was recorded.

\section{OBESITY}

Participants were asked to record their height and weight as measured most recently at their physician's office. BMI was calculated from self-report of height and weight.

\section{Role of THE Funding Source}

This work has been supported by the following research grants to L.B.S.: Thomas F. Jeffress and Kate Miller Jeffress Memorial Trust research grant and VCU Health System BIRCWH award. Neither funding source was involved in the study design, collection or analysis of data, manuscript preparation or decision to submit the manuscript for publication.

\section{RESULTS}

\section{CHARACTERISTICS OF THE COHORT}

Table 2 shows the baseline information and distribution of characteristics in the cohort. The total number of subjects was $88.89 \%$ of subjects were female. The mean age of the cohort was 50.4 years. The mean age at diagnosis of $\mathrm{PH}$ was 44.2 years. A high rate of obesity was observed as the mean BMI was $31.7 \mathrm{~kg} / \mathrm{m}^{2}$. $56 \%$ of participants reported having primary (familial or idiopathic) pulmonary hypertension. Individuals reporting $\mathrm{PH}$ associated with various diseases included the following: 21 patients with collagen vascular disease (RA, scleroderma, CREST), 5 patients with OSA, 6 patients with congenital or acquired cardiac disease (systemic to pulmonary shunt, valvular disease), $1 \mathrm{pa}-$ tient with portal hypertension, 1 patient with COPD, 1 patient with HIV and 1 patient with chronic thromboembolic disease. Lastly, 3 individuals reported anorexigen related $\mathrm{PH}$. PH treatment included prostacyclin therapy in 37, endothelin receptor antagonists in 39 , and PDE-5 inhibitors in 46 and calcium channel blockers in 10 patients. 48 subjects were on multiple drug therapy.

Table 2

\section{Baseline Characteristics}

No. of subjects

88

Males

Females

$\mathrm{BMI}>30 \mathrm{~kg} / \mathrm{m}^{2}$

Mean Age (years)

Mean Age at diagnos is of $\mathrm{PH}$ (years)

Mean BMI $(\mathrm{kg} / \mathrm{m} 2)$

Etiology of $\mathrm{PH}$

Primary (Famililal or Idipathic)

Associated forms

Collagen vascular disease

Chronic cardiac disease

Portal hypertension

Chronic lung disease

Obstructive sleep apnea

HIV

Thromboembolic disease

Anorexigen

10

78

22

50.4

44.2

31.7

49

39

21

6

1

5

1

1

3

Drug therapy for $\mathrm{PH}$

Prostacyclin/Analog

37

Endothelin receptor antagonist

PDE-5 inhibitor

39

Calcium channel blocker

46

10

Multiple drug therapy

48

\section{REPRODUCTIVE FACTORS}

For decades there has been considerable interest in the female predominance of pulmonary hypertension. This has generated important questions regarding the potential for endogenous and exogenous estrogens to 
Table 3.

\section{Reproductive Characteristics of Female PAH Patients}

\begin{tabular}{|c|c|c|}
\hline Prer & hopausal & Postmenopausal \\
\hline No. of subjects & 42 & 36 \\
\hline $\mathrm{BMI}>30 \mathrm{~kg} / \mathrm{m}^{2}$ & 22 & 22 \\
\hline History of fewer than 8 periods/year & 12 & 9 \\
\hline History of infertility & 6 & 0 \\
\hline history of acne & 3 & 3 \\
\hline history of excess hair & 3 & 6 \\
\hline history of PCOS & 1 & 2 \\
\hline \multicolumn{3}{|l|}{ Years of Menstruation } \\
\hline$<15$ & 3 & 0 \\
\hline $15-29$ & 30 & 12 \\
\hline $30-35$ & 6 & 7 \\
\hline$>35$ & 3 & 17 \\
\hline \multicolumn{3}{|l|}{ Menopause status } \\
\hline \multicolumn{2}{|l|}{ Natural menopause } & 17 \\
\hline \multicolumn{2}{|l|}{ Induced menopause } & 19 \\
\hline \multicolumn{2}{|l|}{ Oopherectomy } & 8 \\
\hline \multicolumn{3}{|l|}{ Parity } \\
\hline Parous & 37 & 30 \\
\hline Nulliparous & 5 & 6 \\
\hline \multicolumn{3}{|l|}{ No. of births } \\
\hline 1 & 3 & 5 \\
\hline 2 & 22 & 14 \\
\hline 3 & 8 & 6 \\
\hline 4 & 4 & 3 \\
\hline 5 & 0 & 2 \\
\hline \multicolumn{3}{|l|}{ Use of exogenous female hormones } \\
\hline \multirow{2}{*}{$\begin{array}{l}\text { Never } \\
\text { Past }\end{array}$} & 13 & 2 \\
\hline & 29 & 34 \\
\hline Oral contraceptive pills & 29 & 33 \\
\hline Depo-Provera & 2 & 1 \\
\hline \multicolumn{2}{|l|}{ HRT (oral) } & 24 \\
\hline \multicolumn{2}{|l|}{ HRT (transdermal) } & 2 \\
\hline \multicolumn{2}{|l|}{ Vaginal estrogen cream } & 1 \\
\hline \multicolumn{3}{|l|}{ Current } \\
\hline \multicolumn{2}{|l|}{ Oral contraceptive pills } & \\
\hline HRT (oral) & & 3 \\
\hline Hormone use (years) & & \\
\hline$>10$ & 19 & 20 \\
\hline$>15$ & 1 & 2 \\
\hline$>20$ & 2 & 7 \\
\hline Use of SERMs (EVISTA) & & 2 \\
\hline History of IUD & 3 & 9 \\
\hline History of breast cancer & 0 & 6 \\
\hline Use of tamoxifen & & 6 \\
\hline History of ovarian cancer & 0 & 1 \\
\hline History of breastfeeding & 7 & 26 \\
\hline$>24$ months & & 10 \\
\hline History of DVT & 0 & 3 \\
\hline
\end{tabular}

underlie the observed sex differences. Table 3 shows selective reproductive history characteristics of the female patients in the cohort.

\section{Exogenous Estrogen Exposure}

A significant proportion of female $\mathrm{PH}$ patients reported prior use of exogenous estrogens. $69 \%$ of premenopausal females reported prior use of oral contraceptive pills (OCP), and 1 subject reported current use. $92 \%$ of postmenopausal women reported prior use of OCP and 67\% reported prior use of estrogens in the form of hormone replacement therapy (HRT) following spontaneous or induced menopause. 3 subjects reported current use of HRT. These rates exceed estimates of OCP and HRT usage as compared to data derived from NHANES [25-26]. In the premenopausal subgroup, $45 \%$ the reported less than 10 yrs of OCP use, whereas $56 \%$ of postmenopausal women reported greater than 10 years of exogenous estrogen use. 2 subjects reported greater than 15 years and 7 subjects reported greater than 20 years of estro- 
gen exposure. While specific data was not collected regarding the timing of estrogen therapy relative to diagnosis of $\mathrm{PH}$, the mean age of the entire cohort was 50.4 years and the mean age at diagnosis was 44.2 years. As a majority of subjects in the postmenopausal group reported greater than 10 years of estrogen exposure, it is very likely that exogenous estrogen exposure occurred prior to diagnosis of pulmonary hypertension in this group. Among females reporting diagnosis of $\mathrm{PH}$ prior to 40 years of age, $75 \%$ also reported prior use of OCP.

\section{LifELONG Estrogen Exposure}

In an effort to roughly quantify lifelong estrogen exposure (load) we evaluated female PAH patients with regards to several major epidemiologic risk factors (some conferring increased risk and others conferring protection) which have been identified in studies of hormone responsive cancers. These included obesity, parity, total years of menstruation, exogenous hormone usage, history of ovarian or breast cancer, history of prolonged breast feeding, and ingestion of soy isoflavones. Collectively these factors were used to generate point system which was applied to each subject. Figure 1 depicts the proportion of risk factors points reported by subjects according to their menopause status. This assessment of reproductive history revealed that only $16 \%$ of premenopausal females reported none of these reproductive risk factors. A large proportion of these patients had either familial PAH or PAH associated with collagen vascular disease. With regards to the existence of multiple risk factor points, $29 \%$ of the premenopausal and $46 \%$ of postmenopausal women reported greater than 4 risk factors points. Regarding estrogen responsive cancers in the subgroup, 5 women reported breast cancer treated with anti-estrogen therapy. Of 3 subjects reporting DVT, all had used OCP and one individual had a concurrent history of breast cancer.

\section{Prevalence of Thyroid Disease}

For the purposes of our study, thyroid disease was defined as "overt" hypo or hyperthyroidism requiring therapy or thyroid cancer. Several subjects reported a history of benign nodular thyroid disease or subclinical hypothyroidism, but these were not included for analysis. Table 2 shows the distribution of thyroid disease per self-report. The prevalence of self-reported thyroid disease in our cohort was $41 \%$. While previous studies have reported as much as three-fold increase in prevalence of thyroid disease in PAH patients [27], our cohort reported thyroid disease at a rate six times that of large population based estimates of thyroid disease [28].

The percentage of subjects reporting thyroid disease was as follows: $84 \%$ of patients with thyroid disease reported having hypothyroidism, 8\% reported having hyperthyroidism and $8 \%$ reported a history of thyroid cancer. The highest prevalence of thyroid disease was reported by patients aged 60-69 years and the lowest prevalence was reported by those aged 20-29 years. Although no discrete pattern emerged, there was a trend towards an age related increase in prevalence of thyroid disease. Controversy currently exists regarding the potential for prostacyclin therapy to induce or "unmask" thyroid disease [29]. The largest proportion of patients reporting both thyroid disease and current prostacyclin therapy occurred in the 30-39 year old group. This may explain the higher than expected prevalence of thyroid disease in this relatively young subgroup.

\section{Thyroid Disease according to PH Subtype}

$41 \%$ of patients with "secondary" $\mathrm{PH}$ reported thyroid disease as compared to $38 \%$ of patients with primary disease. Nearly $50 \%$ of patients with "secondary" PAH and thyroid disease had collagen vascular disease (CREST syndrome, RA, scleroderma) which might reflect enhanced susceptibility to autoimmune disorders in these individuals. Several studies have reported associations between subclinical or overt thyroid disease and sleep disordered breathing [30]. Among individuals in our cohort with pulmonary hypertension secondary to OSA, 75\% reported thyroid disease. The mean BMI of this group was 45.9 $\mathrm{kg} / \mathrm{m}^{2}$. All individuals with OSA reported a diagnosis of hypothyroidism and current treatment with thyroid replacement hormone.

\section{Prevalence of OBesity}

The mean BMI of the entire cohort was $31.7 \mathrm{~kg} / \mathrm{m}^{2}$. $46 \%$ of patients met criteria for obesity as defined by a BMI $>30 \mathrm{~kg} / \mathrm{m}^{2}$ (Fig. 2). The prevalence of obesity was the most pronounced in the 50-59 year old subgroup, followed closely by the 40-49 year old subgroup. The rate of obesity in our cohort exceeds the prevalence of obesity as suggested by NHANES data [31]. 13 subjects were currently on glucocorticoid therapy.

\section{Premenopausal Females}

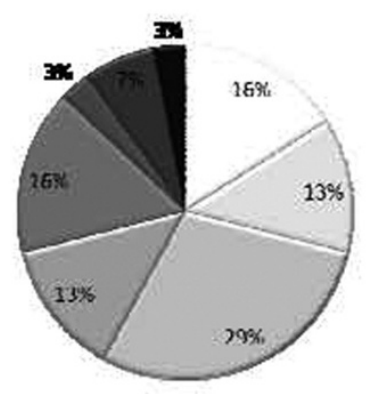

Postmenopausal Females

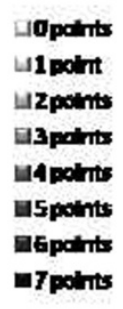

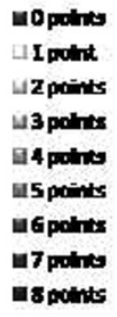

Fig. 1. Reproductive risk factor point distribution for the cohort is shown according to menopause status. 

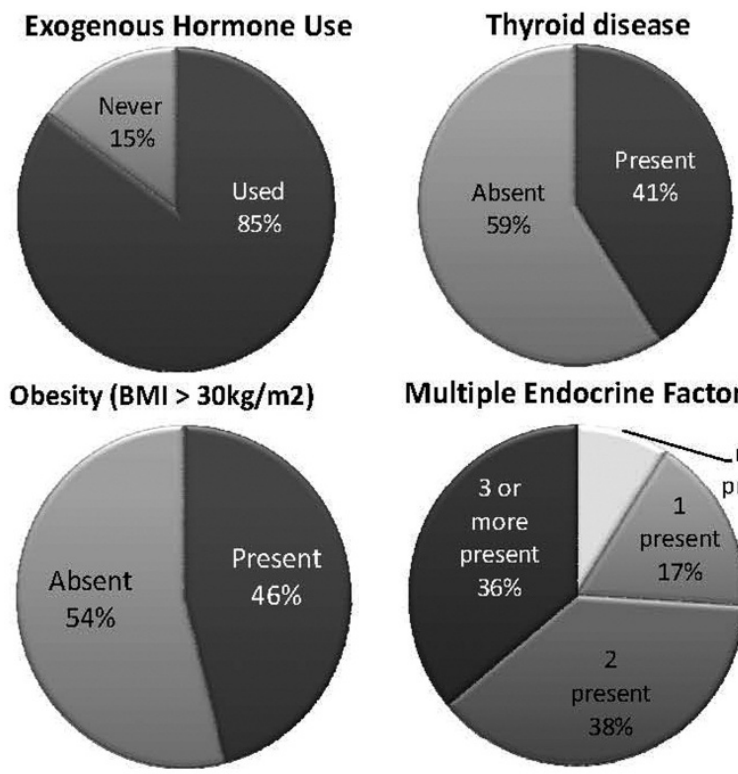

Multiple Endocrine Factors

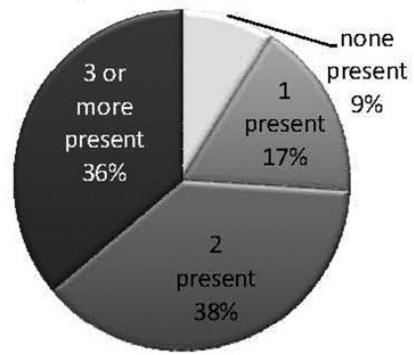

Fig. 2. Distribution of these risk factors and the combination of risk factors.

Prevalence of Multiple Endocrine Risk Factors

We analyzed all females in the cohort for the presence of multiple endocrine risk factors to include BMI $>30$ $\mathrm{kg} / \mathrm{m}^{2}$, previous use of exogenous estrogens and thyroid disease requiring medical therapy. Figure 3 depicts the results. Nine percent of females had no risk factor points and $17 \%$ had one risk factor point. $74 \%$ of patients had multiple endocrine factors points and this group was comprised mostly of postmenopausal females (Fig. 2).

\section{DisCUSSION}

Apparently during the last 20 years more patients in the U.S.A. have received the diagnosis of pulmonary hypertension than in preceding decades [32]. Overall, severe PAH is a group of rare diseases, either idiopathic or associated with known causes. Whereas progress has been made to elucidate the gene mutations which underlie the susceptibility for PAH development in some groups of patients [33] little is known about modifiers of disease or epigenetically important factors and conditions. One of several disease modifiers may be female gender as a greater prevalence of women in all forms of $\mathrm{PAH}$ has been recognized for decades [2]. It is remarkable that the fraction of women, and in particular older women, in most groups of PAH patients has increased in recent years and also that no hypothesis for this gender preference has been developed. Although a causative or permissive role of angiogenic and perhaps proinflammatory estrogen metabolites [34] is now somewhat intuitive, there are no data on cumulative life-long estrogen exposure in $\mathrm{PH}$ patients. Another risk factor for development of PAH is autoimmunity [35]. All forms of autoimmune disorders are more prevalent in women and hormonal factors have been considered to explain this prevalence. Increased rates of autoimmune thyroid disease have been observed in patients with IPAH and many disease-associated forms of pulmonary hypertension [36]. Lastly obesity, now recognized as a complex endocrinopathy with a systemic inflammatory component and a risk factor for hormone-sensitive cancers [37], has recently been reported in women with PAH [7].

In order to survey the prevalence of these individual factors and conditions in a cohort of patients with the diagnosis of severe PAH, both a focused endocrine disorder questionnaire was administered and an interview was conducted. Here we report a high prevalence of long-term estrogen exposure, thyroid disorder and obesity in this cohort of PAH patients. As the overwhelming number of patients in this cohort were women, we focus the following discussion on the female patients' characterization.

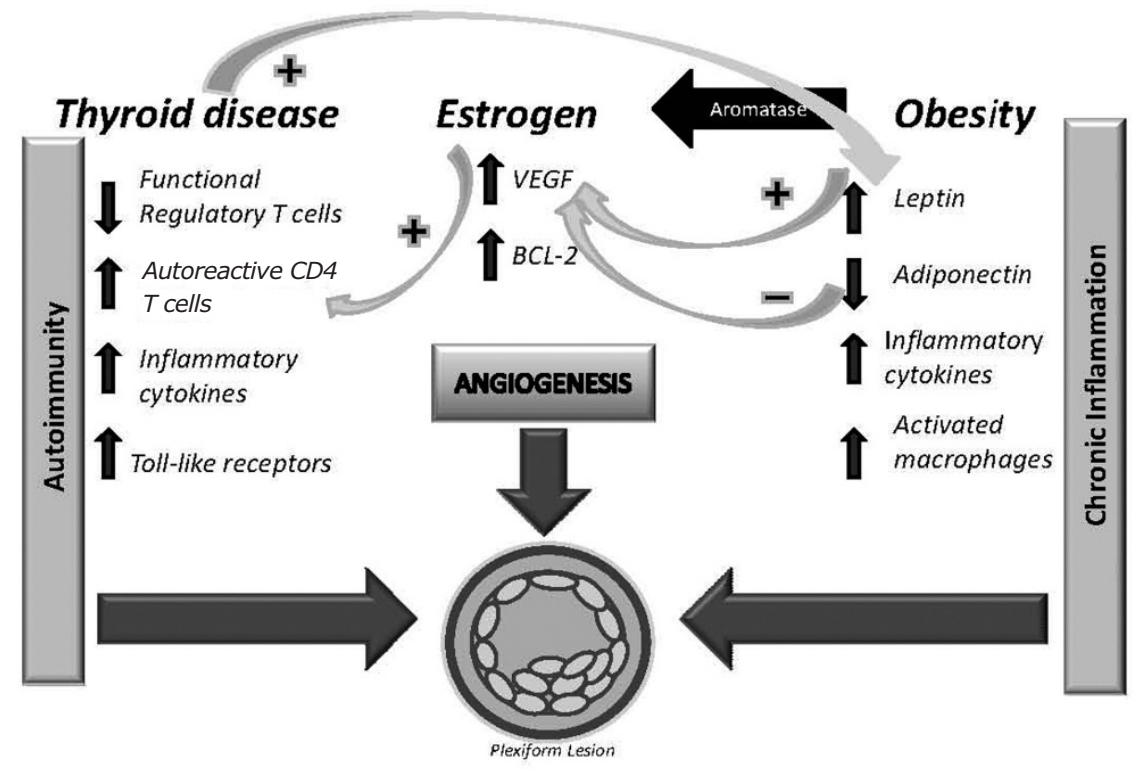

Severe Angioproliferative Pulmonary Hypertension
Fig. 3. Schematic illustrating the potential interactions of pathobiologically relevant risk factos which may contribute to severe angioproliferative pulmonary arterial hypertension. Hypothetically, autoimmunity and chronic inflammation interact via thyroid disease, estrogen and obesity.

VEGF = vascular endothelial growth factor, Bcl-2 = antiapoptotic B-cell lymphoma protein 


\section{LONG-TERM ESTROGEN EXPOSURE}

Early and long term estrogen exposure has been correlated with an increased risk for the development of hormone responsive cancers. There is also accumulating evidence that estrogen is a key regulator of endothelial cell proliferation and function in vivo [38]. Similar mechanisms which underlie both carcinogenesis and endothelial cell proliferation include estrogen induced VEGF expression, decreased synthesis of proteins required for apoptosis and up-regulation of protective genes in cell death pathways [39]. Given our current understanding of the pathology of $\mathrm{PAH}$ which includes the phenotype switch of pulmonary vascular endothelium into a highly proliferative, apoptosis-resistant phenotype [40], we have a growing interest in estrogen exposure in the context of PAH. As such, we were particularly impressed with the rates of self-reported hormone therapy in our cohort. Indeed $71 \%$ of the premenopausal and $86 \%$ of the postmenopausal women reported previous or current use of hormone therapy. In the postmenopausal subgroup, more than $50 \%$ of patients reported greater than 10 years of hormone therapy, which was most commonly a prolonged use of oral contraceptive pills. While we intentionally avoided questions regarding hormone dose and estrogen/progestin composition, the OCP preparations commonly prescribed to women of a similar age as our post-menopausal subgroup consisted of higher dose estrogen than is commonly prescribed today [41]. This prominent use of hormone therapy was reflected in our scoring of lifelong estrogen exposure in our cohort. In fact, in postmenopausal patients, obesity and prolonged hormone therapy were the most significant contributors to our putative risk factor score. Of interest, is the observation that only a small proportion of women had no risk factors. These were young women (average age $<22$ years) with either familial IPAH or PAH associated with CREST syndrome. Perhaps in these individual women, genetic or disease associated factors are prominent enough to promote the development of $\mathrm{PAH}$, and the contribution of a "second hit" is less important. It may also be of interest that the use of phytoestrogens was common in this patient cohort.

\section{Autoimmune Thyroid Disease}

It has been established that a higher prevalence of autoimmune thyroid disease exists in $\mathrm{PH}$ patients, and that anti-thyroid antibodies can be detected in patients without overt thyroid dysfunction at rates higher than the general population [40]. Thyrotoxicosis has also been considered a risk factor for pulmonary arterial hypertension, and treatment with thionamides in this population can reverse PAH [43-44]. We found a high proportion of patients in our cohort reporting a history of thyroid disease and current use of thyroid hormone supplementation. Indeed thyroid disease among our patients was prevalent at a rate nearly double that recently published by Burger and colleagues at Mayo Clinic [45]. In their retrospective study thyroid disease was defined as abnormal TSH, history of thyroid disease on replacement or elevated TPO antibody. While we did rely on self-report of thyroid disease in our study, we defined individuals as having thyroid dysfunction only if they required medical therapy. Of course we do not have information on the severity of thyroid gland dysfunction at the time of initiation of therapy, so it is possible that some patients were currently on therapy for subclinical thyroid disease.

The majority of patients reporting thyroid disease were hypothyroid and a significant proportion also reported current therapy with prostacyclin or prostacyclin analogs. There has been a longstanding interest in the potential of prostacyclin to induce thyroid disease in PAH patients [46]. Indeed thyroid tissue has high and low affinity receptors for prostacyclin and alterations in receptor density and kinetics have been observed in Hashimoto's, Reidel thyroiditis, autonomous thyroid nodules and thyroid cancer [47]. Prostacyclin infusion can also enhance TSH secretion and promote peripheral conversion of T4 to T3 [48]. Currently there is no consensus regarding the importance of establishing baseline thyroid function in patients with $\mathrm{PAH}$, nor in monitoring thyroid function prior to or after the initiation of prostacyclin therapy. Additionally, there have been no studies to date which have evaluated the treatment of subclinical thyroid dysfunction in this population. Treatment of thyroid dysfunction in PAH may have important pathobiological consequences. While the effects of thyroid hormone on lung ventilation/oxygenation and peripheral vascular resistance [49] have been characterized for some time, new evidence suggests that thyroid hormone through non-genomic signaling may induce proliferation and promote migration of human arterial smooth muscle cells [50].

\section{OBESITY}

The high prevalence of obesity in our cohort echoes recent findings from larger $\mathrm{PH}$ surveys and may be important in the pathobiology of PH. It is now recognized that obesity is a systemic process characterized by chronic inflammation, pro-angiogenesis and impaired immune function [51]. Adipose tissue is a dynamic organ capable of synthesis and secretion of proinflammatory cytokines, hormones (adipokines) and potent growth factors which have local paracrine and systemic effects [52]. The accumulation of intraabdominal fat leads to impaired insulin signaling, and decreased intracellular glucose transport [53]. These signaling defects result in impaired endothelium-dependent vasodilation [54]. Additionally, obesity is associated with characteristic changes in the proportion of adipose derived hormones. Fat-pad production of adiponectin and ghrelin is decreased, and the production of leptin is increased with caloric excess [55]. While these hormones have well established roles in energy homeostasis, current research also suggests that they may be important regulators of angiogenesis [56]. Adiponectin has been shown to inhibit tumor cell proliferation, microvessel angiogenesis and VEGF-induced migration of coronary artery endothelial cells [57]. Conversely, leptin is mitogenic to vascular endothelium and and coronary artery smooth muscle cells, likely through upregulation of VEFGR-1 [58]. 
Leptin also induces matrix remodeling through upregulation of matrix metalloproteinases [59]. Our understanding of the relationship between obesity and innate immunity now extends beyond the concept of chronic inflammation resulting in immune dysfunction (Fig. 3). The fat pad is a reservoir for macrophages which are functionally similar to "M1" or classically activated macrophages [60], and the immunodeficiency of obesity involves defective T-cell to mitogen response, and decreased NK cell activity [61]. There are also overlapping defects in key signaling pathways in obesity and PH. It is intriguing that TGF- $\beta$ signaling is impaired in $\mathrm{PH}$ and that proper signaling through this pathway is key to the regulation of satiety in humans (through DAF-7) [62]. This has interesting implications regarding potential therapies targeted to both $\mathrm{PH}$ and obesity.

As investigators are beginning to consider PAH disease modifiers, each of these putative factors or conditions present in our cohort could indeed represent an initiating or disease modifying factor. Although the rationale for hypothetically linking long-term estrogen exposure, autoimmune thyroid disease and obesity with the development of PAH (Fig. 3) is attractive, our approach to data gathering and data analysis can provide circumstantial evidence at best. Neither long term estrogen exposure nor obesity have previously been considered important risk or trigger factors for PAH. Abehaim et al. [63] in their prospective case control study of anorexigen induced PAH could not establish a statistically significant link between obesity and $\mathrm{PAH}$, however the cohort studied was European and obesity is still less prevalent in Europe as compared to the US population. Overall larger multicenter cohorts have not been evaluated for the presence or prevalence of these putative risk factors and the concept of potentially important epigenetic factors in the development of PAH are not generally accepted. It is evident that hypothesis-driven mining of databases requires the inclusion of data which are pertinent to the subject under investigation and it is therefore regrettable that the recently established REVEAL pulmonary hypertension data bank does not contain elements of the reproductive history of women. As there is presently no general acceptance of a concept of epigenetic modifiers, there is certainly no appreciation for a potential confluence or interaction of multiple (at present putative) factors. Indeed the data derived from our questionnaire and interview document that the majority of the PAH patients presented with more than one of these putative risk factors, in fact, nearly three-quarters of these patients presented with more than one of these factors.

\section{LIMITATIONS}

Clearly, like any relatively small cohort study, ours has a number of limitations and the results are in some danger of over-interpretation. We chose to investigate patients attending the 2008 International Pulmonary Hypertension Association meeting and these individuals represent a subset highly motivated to participate in clinical studies. As such, our findings might not be generalizable to larger groups of $\mathrm{PAH}$ patients. Addi- tionally, many patients were from specialized $\mathrm{PAH}$ treatment centers in the US. It could be argued that this group likely has enhanced access to medical care such that surveillance for and diagnosis of thyroid disease could have been increased. Second, our study design included a self-administered questionnaire and personal interview and relied largely upon recall of clinical data, and as such, was subject to recall bias. Previous studies which have compared recalled and validated elements of the reproductive history have shown fair to excellent agreement in personal recall of onset and duration of menses, parity, and use of hormone therapy. Less agreement has been observed in recall of hormone preparation, duration of hormone therapy and onset of menopause [64-65]. Also, as we relied upon self-report of most recent height and weight when calculating BMI, our results likely represent an underestimation of true BMI. Several studies suggest that self-reported weight can vary by as much as 3 kilograms from measured weight and that in most cases it is underestimated [66]. Lastly, as some of our questions could be considered sensitive, and the patient interview was conducted by a single board-certified endocrinologist, the potential exists for both interviewer and respondent bias to have influenced our results. Furthermore, the questionnaire used here has not been previously validated in the form presented to these PAH patients, although the composition of the questions is similar to those commonly used in the field of hormone-sensitive cancer epidemiology. Our decision to use an arbitrary point score system in order to attempt a more quantitative assessment of estrogen exposure was entirely ours and may be subject to severe criticism. Finally, we need to emphasize that our process of data gathering amounts to little more than a first survey of a potentially very complex interplay between genetic and endocrine risk factors in female patients with PAH. Nevertheless, the results of our survey can be seen as hypothesis-generating and may provide the basis for the design of a prospective multi-center study of women with PAH which would focus on these putative risk factors. Such a study would rely upon a questionnaire similar to ours and would for its analysis not rely upon comparative data derived from existing databases.

\section{Acknowledgement}

This work has been supported by the following research grants to L.B.S.: Thomas F. Jeffress and Kate Miller Jeffress Memorial Trust research grant and VCU Health System BIRCWH award.

The authors wish to thank the Pulmonary Hypertension Association (PHA) leadership, in particular Dr. Greg Elliott (Intermountain Medical Center University of Utah School of Medicine ) and the pulmonary hypertension patients who consented to participate in this survey. We also wish to thank Dr. John Nestler (Virginia Commonwealth University School of Medicine) for his critical reading of this manuscript.

Authors' contributions

I declare that I have participated in study design, collection and interpretation of data, writing of the manuscript, and the decision to submit the manuscript for publication. I have no conflicts of interest with regards to this research. Lori B. Sweeney, M.D.

I declare that I have participated in study design, interpretation of data, writing of the manuscript and the decision to submit the manuscript for publication. I have no conflicts of interest with regards to this research. Norbert F. Voelkel, M.D. (Corresponding author) 


\section{REFERENCES}

1. Simonneau G, Galie N, Rubin LJ, Langleben D, Seeger W, Domenighetti G, et al. Clinical classification of pulmonary hypertension. J Am Coll Cardiol 2004 Jun 16; 43(12 Suppl S):5S-12S.

2. Voelkel NF, Reeves JT. Lung Biology in Health and Disease. Primary Pulmonary Hypertension in Pulmonary Vascular Diseases.New York: Marcel Dekker; 1979. p. 573-628.

3. Rich S, Dantzker DR, Ayres SM, Bergofsky EH, Brundage BH, Detre KM, et al. Primary pulmonary hypertension. A national prospective study. Ann Intern Med 1987 Aug;107(2):216-23.

4. Hill NS, Preston IR, Roberts KE. Patients with Pulmonary Arterial Hypertension in Clinical Trials. Who Are They? Proc Am Thorac Soci 2008;5:603-9.

5. Badesch DB, Benza RL, Krichman AM, Raskob GE, Giles S. REVEAL REGISTRY: BASELINE CHARACTERISTICS OF THE FIRST 1,226 ENROLLED PATIENTS. Chest Meeting Abstracts 2007 Oct 1;132(4): 473b-474.

6. Maradit-Kremers H, Golbin JM, Slusser JP, Scott CG, Kane GC, McGoon MD. Treatment patterns and predictors of drug therapy in pulmonary arterial hypertension (PAH) between 1995 and 2005. Mayo Clinic, Rochester, MN, USA; 2008.

7. Taraseviciute A, Voelkel NF. Severe pulmonary hypertension in postmenopausal obese women. Eur J Med Res 2006 May 5;11(5):198-202.

8. Deng Z, Morse JH, Slager SL, Cuervo N, Moore KJ, Venetos $G$, et al. Familial primary pulmonary hypertension (gene PPH1) is caused by mutations in the bone morphogenetic protein receptor-II gene. Am J Hum Genet 2000 Sep;67(3):737-44.

9. Harrison RE, Flanagan JA, Sankelo M, Abdalla SA, Rowell J, Machado RD, et al. Molecular and functional analysis identifies ALK-1 as the predominant cause of pulmonary hypertension related to hereditary haemorrhagic telangiectasia. J Med Genet 2003 Dec;40(12):865-71.

10. Newman JH, Trembath RC, Morse JA, Grunig E, Loyd JE, Adnot S, et al. Genetic basis of pulmonary arterial hypertension: current understanding and future directions. J Am Coll Cardiol 2004 Jun 16;43(12 Suppl S):33S-9S.

11. Sitbon O, Lascoux-Combe C, Delfraissy JF, Yeni PG, Raffi F, De ZD, et al. Prevalence of HIV-related pulmonary arterial hypertension in the current antiretroviral therapy era. Am J Respir Crit Care Med 2008 Jan 1; 177(1):108-13.

12. Galie N, Manes A, Palazzini M, Negro L, Marinelli A, Gambetti S, et al. Management of pulmonary arterial hypertension associated with congenital systemic-to-pulmonary shunts and Eisenmenger's syndrome. Drugs 2008;68(8):1049-66.

13. Wassink AM, Olijhoek JK, Visseren FL. The metabolic syndrome: metabolic changes with vascular consequences. Eur J Clin Invest 2007 Jan;37(1):8-17.

14. Ferris A, Jacobs T, Widlitz A, Barst RJ, Morse JH. Pulmonary arterial hypertension and thyroid disease. Chest 2001 Jun;119(6):1980-1.

15) Nicolls MR, Taraseviciene-Stewart L, Rai PR, Badesch DB, Voelkel NF. Autoimmunity and pulmonary hypertension: a perspective. Eur Respir J 2005 Dec;26(6):11108.

16. Humbert M, Morrell NW, Archer SL, Stenmark KR, MacLean MR, Lang IM, et al. Cellular and molecular pathobiology of pulmonary arterial hypertension. J Am Coll Cardiol 2004 Jun 16;43(12 Suppl S):13S-24S.

17. La VC, Negri E, Franceschi S, Parazzini F. Long-term impact of reproductive factors on cancer risk. Int J Cancer 1993 Jan 21;53(2):215-9.
18. Ko KP, Park SK, Kim Y, Bae J, Jun JK, Gwack J, et al. [Reliability of a questionnaire for women's reproductive history]. J Prev Med Public Health 2008 May;41(3): 181-5.

19. Layde PM, Webster LA, Baughman AL, Wingo PA, Rubin GL, Ory HW. The independent associations of parity, age at first full term pregnancy, and duration of breastfeeding with the risk of breast cancer. Cancer and Steroid Hormone Study Group. J Clin Epidemiol 1989;42(10): 963-73.

20. Eliassen AH, Hankinson SE. Endogenous hormone levels and risk of breast, endometrial and ovarian cancers: prospective studies. Adv Exp Med Biol 2008;630:148-65.

21. Vona-Davis L, Howard-McNatt M, Rose DP. Adiposity, type 2 diabetes and the metabolic syndrome in breast cancer. Obes Rev 2007 Sep;8(5):395-408.

22) Breast cancer and combined oral contraceptives: results from a mulit-national study: WHO collaborative study of neoplasia and steroid contraceptives. Br J Cancer 1990; 61(1):110-9.

23. Messina MJ, Loprinzi CL. Soy for breast cancer survivors: a critical review of the literature. J Nutr 2001 Nov;131(11 Suppl):3095S-108S.

24. Maskarinec G, Singh S, Meng L, Franke AA. Dietary soy intake and urinary isoflavone excretion among women from a multiethnic population. Cancer Epidemiol Biomarkers Prev 1998 Jul;7(7):613-9.

25. Crespo CJ, Smit E, Snelling A, Sempos CT, Andersen RE. Hormone replacement therapy and its relationship to lipid and glucose metabolism in diabetic and nondiabetic postmenopausal women: results from the Third National Health and Nutrition Examination Survey (NHANES III). Diabetes Care 2002 Oct;25(10):1675-80.

26. Taichman LS, Eklund SA. Oral contraceptives and periodontal diseases: rethinking the association based upon analysis of National Health and Nutrition Examination Survey data. J Periodontol 2005 Aug;76(8):1374-85.

27. Li JH, Safford RE, Aduen JF, Heckman MG, Crook JE, Burger CD. Pulmonary hypertension and thyroid disease. Chest 2007 Sep;132(3):793-7.

28. Aoki Y, Belin RM, Clickner R, Jeffries R, Phillips L, Mahaffey KR. Serum TSH and total T4 in the United States population and their association with participant characteristics: National Health and Nutrition Examination Survey (NHANES 1999-2002). Thyroid 2007 Dec;17(12): 1211-23.

29. Arroliga AC, Dweik RA, Rafanan AL. Primary pulmonary hypertension and thyroid disease. Chest 2000 Oct;118(4): 1224-5.

30. Resta O, Pannacciulli N, Di GG, Stefano A, Barbaro MP, De PG. High prevalence of previously unknown subclinical hypothyroidism in obese patients referred to a sleep clinic for sleep disordered breathing. Nutr Metab Cardiovasc Dis 2004 Oct;14(5):248-53.

31. Flegal KM, Carroll MD, Ogden CL, Johnson CL. Prevalence and trends in obesity among US adults, 1999-2000. JAMA 2002 Oct 9;288(14):1723-7.

32. Hyduk A, Croft JB, Ayala C, Zheng K, Zheng ZJ, Mensah GA. Pulmonary hypertension surveillance--United States, 1980-2002. MMWR Surveill Summ 2005 Nov $11 ; 54(5): 1-28$.

33. Newman JH, Trembath RC, Morse JA, Grunig E, Loyd JE, Adnot S, et al. Genetic basis of pulmonary arterial hypertension: current understanding and future directions. J Am Coll Cardiol 2004 Jun 16;43(12 Suppl S):33S-9S.

34. Yager JD, Davidson NE. Estrogen carcinogenesis in breast cancer. N Engl J Med 2006 Jan 19;354(3):270-82.

35. Badesch DB, Wynne KM, Bonvallet S, Voelkel NF, Ridgway C, Groves BM. Hypothyroidism and primary pulmonary hypertension: an autoimmune pathogenetic link? Ann Intern Med 1993 Jul 1;119(1):44-6. 
36. Arroliga AC, Dweik RA, Rafanan AL. Primary pulmonary hypertension and thyroid disease. Chest 2000 Oct;118(4): 1224-5.

37. Rinaldi S, Key TJ, Peeters PH, Lahmann PH, Lukanova A, Dossus L, et al. Anthropometric measures, endogenous sex steroids and breast cancer risk in postmenopausal women: a study within the EPIC cohort. Int J Cancer 2006 Jun 1;118(11):2832-9.

38. Applanat MP, Buteau-Lozano H, Herve MA, Corpet A. Vascular endothelial growth factor is a target gene for estrogen receptor and contributes to breast cancer progression. Adv Exp Med Biol 2008;617:437-44.

39. Lee MY, Jung SC, Lee JH, Han HJ. Estradiol-17beta protects against hypoxia-induced hepatocyte injury through ER-mediated upregulation of Bcl-2 as well as ER-independent antioxidant effects. Cell Res 2008 Apr;18(4):491-9.

40. Rai PR, Cool CD, King JAC, Stevens T, Burns N, Winn RA, et al. The Cancer Paradigm of Severe Pulmonary Arterial Hypertension. Am J Respir Crit Care Med 2008 Sep 15;178(6):558-64.

41. Casey PM, Cerhan JR, Pruthi S. Oral contraceptive use and risk of breast cancer. Mayo Clin Proc 2008 Jan;83(1): 86-90.

42. Arroliga AC, Dweik RA, Rafanan AL. Primary pulmonary hypertension and thyroid disease. Chest 2000 Oct;118(4): 1224-5.

43. Ma RC, Cheng AY, So WY, Hui DS, Tong PC, Chow CC. Thyrotoxicosis and pulmonary hypertension. Am J Med 2005 Aug;118(8):927-8.

44. Siu CW, Zhang XH, Yung C, Kung AW, Lau CP, Tse HF. Hemodynamic changes in hyperthyroidism-related pulmonary hypertension: a prospective echocardiographic study. J Clin Endocrinol Metab 2007 May;92(5):1736-42.

45. Li JH, Safford RE, Aduen JF, Heckman MG, Crook JE, Burger CD. Pulmonary hypertension and thyroid disease. Chest 2007 Sep;132(3):793-7.

46. Ferris AM, Morse JH, Barst RJ. Thyroid disease and pulmonary arterial hypertension $(\mathrm{PAH})$ in patients treated with prostacylin. Circulation 102[18], (suppl II) 426. 2000. Ref Type: Abstract

47. Virgolini I, Steurer G, Keminger K, Sinzinger H, Kraupp O. Evaluation of prostaglandin receptors in the human thyroid gland. Prog Clin Biol Res 1987;242:35-42.

48. Mitsuma T, Nogimori T, De HS, Chaya M. Effect of prostaglandin $\mathrm{A} 1$ and $\mathrm{A} 2$ on thyrotropin secretion in rats. Endocrinol Exp 1986 Dec;20(4):371-7.

49. Vinzio S, Morel O, Schlienger JL, Goichot B. [Cellular mechanisms of thyroid hormone action]. Presse Med 2005 Sep 24;34(16 Pt 1):1147-52.

50. Kasahara T, Tsunekawa K, Seki K, Mori M, Murakami M. Regulation of iodothyronine deiodinase and roles of thyroid hormones in human coronary artery smooth muscle cells. Atherosclerosis 2006 May;186(1):207-14.

51. Karagiannides I, Pothoulakis C. Obesity, innate immunity and gut inflammation. Curr Opin Gastroenterol 2007 Nov;23(6):661-6.

52. Bakhai A. Adipokines--targeting a root cause of cardiometabolic risk. QJM 2008 Jun 10.

53. Despres JP. Health consequences of visceral obesity. Ann Med 2001 Nov;33(8):534-41.

54. Zhang C. The role of inflammatory cytokines in endothelial dysfunction. Basic Res Cardiol. 2008 Sep;103(5):398406.
55. Bays HE, Gonzalez-Campoy JM, Bray GA, Kitabchi AE, Bergman DA, Schorr AB, et al. Pathogenic potential of adipose tissue and metabolic consequences of adipocyte hypertrophy and increased visceral adiposity. Expert Rev Cardiovasc Ther 2008 Mar;6(3):343-68.

56. Hausman GJ, Richardson RL. Adipose tissue angiogenesis. J Anim Sci 2004 Mar;82(3):925-34.

57. Kelesidis I, Kelesidis T, Mantzoros CS. Adiponectin and cancer: a systematic review. Br J Cancer 2006 May 8; 94(9):1221-5.

58. Cao R, Brakenhielm E, Wahlestedt C, Thyberg J, Cao Y. Leptin induces vascular permeability and synergistically stimulates angiogenesis with FGF-2 and VEGF. Proc Natl Acad Sci U S A 2001 May 22;98(11):6390-5.

59. Park HY, Kwon HM, Lim HJ, Hong BK, Lee JY, Park $\mathrm{BE}$, et al. Potential role of leptin in angiogenesis: leptin induces endothelial cell proliferation and expression of matrix metalloproteinases in vivo and in vitro. Exp Mol Med 2001 Jun 30;33(2):95-102.

60. Heilbronn LK, Campbell LV. Adipose tissue macrophages, low grade inflammation and insulin resistance in human obesity. Curr Pharm Des 2008;14(12):1225-30.

61. Nieman DC, Henson DA, Nehlsen-Cannarella SL, Ekkens M, Utter AC, Butterworth DE, et al. Influence of obesity on immune function. J Am Diet Assoc 1999 Mar; 99(3):294-9.

62. You YJ, Kim J, Raizen DM, Avery L. Insulin, cGMP, and TGF-beta signals regulate food intake and quiescence in C. elegans: a model for satiety. Cell Metab 2008 Mar;7(3): 249-57.

63. Rich S, Rubin L, Walker AM, Schneeweiss S, Abenhaim L. Anorexigens and pulmonary hypertension in the United States: results from the surveillance of North American pulmonary hypertension. Chest 2000 Mar;117(3): 870-4.

64. Bosetti C, Tavani A, Negri E, Trichopoulos D, La VC. Reliability of data on medical conditions, menstrual and reproductive history provided by hospital controls. J Clin Epidemiol 2001 Sep;54(9):902-6.

65. Nischan P, Ebeling K, Thomas DB, Hirsch U. Comparison of recalled and validated oral contraceptive histories. Am J Epidemiol 1993 Nov 1;138(9):697-703.

66. Shields M, Gorber SC, Tremblay MS. Estimates of obesity based on self-report versus direct measures. Health Rep 2008 Jun;19(2):61-76.

Received: June 19, 2009 / Accepted: June 24, 2009

Address for correspondencer:

Norbert Voelkel, M.D.

Department of Internal Medicine

Pulmonary and Critical Care Medicine Division

1220 East Broad Street

MMRB II Room 6052

Richmond

Virginia 23298

USA

Phone: 804-628-9614

Fax: $\quad$ 804-628-0325

E-mail: nvoelkel@mcvh-vcu.edu 